\title{
Social Phobia among Tramadol and Opioid Users
}

\author{
AMIRA ELSAIED ELASHRY, M.Sc.; HOSSAM ELDIEN FATHALLAH ELSAWY, M.D.; \\ AMR ADEL HAIBA, M.D. and SHEREEN DESOKY ABOHAMAR, M.D.
}

The Department of Neuropsychiatry, Faculty of Medicine, Tanta University

\begin{abstract}
Background: Substance use disorder is a global health problem as it is associated with a lot of disabilities e.g. occupational, familial, financial and psychological. Cooccurrence of Tramadol and Opioid use disorder is more frequent among subjects with generalized anxiety, social phobia or depression and these psychiatric disorders may trigger substance use.
\end{abstract}

Aim of Study: The purpose of this study was to identify the relationship between social phobia and tramadol and opioid use, and if it has a role in starting drug use.

Patients and Methods: A sequential sample of 103 Tramadol and/or Opioid users of both genders, 18-50 years old was collected from patients admitted to Psychiatry, Neurology and Neuro-Surgery Center in Tanta University through the period from the first of June to the end of December 2017. Social phobia was assessed by Raulin and Wee scale for social phobia.

Results: Tramadol users had obviously increased level of social phobia after one month of withdrawal. Although opioid users had a higher level of social phobia at base line, the level of social phobia didn't increase by the same degree of tramadol. Among tramadol users depression increased after one month while among opioid users depression was severe at base line then decreased gradually. Users of both drug experience lower level of depression than those of opioid users only. Tramadol users had little variation of anxiety all over the study while users of opioid had higher level of anxiety that increased after one month of withdrawal.

Conclusion: Tramadol withdrawal leads to significant social phobia and depression that should be proberly treated while Opioid use disorder leads to significant depression especially with longer duration of drug use.

Key Words: Social phobia-Tramadol and Opioid.

\section{Introduction}

SUBSTANCE abuse is a global health problem as it is associated with a lot of disabilities e.g. occupational, familial, financial and psychological [1].

Correspondence to: Dr. Amira Elsaied Elashry, The Department of Neuropsychiatry, Faculty of Medicine, Tanta University
The main cause of substance use is unknown but various studies reported that there is strong relation between substance use and psychiatric disorders e.g. mental illness lead to substance use, substance use may lead to mental illness both may occur separately and both may be caused by common factor. While several studies show link between psychiatric disorder and drug use, it's still questionable who start first $[2,3]$.

Despite the harmful sequelae of drug use mentioned above, it's proved that chronic drug use alters anatomy and biochemistry of the brain that's why addicted persons are at high risk of recurrence because these changes lasts for months or years after abstinence, so associated psychiatric problems should be treated and patients must be taught new skills to avoid reuse of the drug [4].

Opiate is a term classically used in pharmacology to mean a drug derived from opium. Opioid, a more modern term, is used to designate all narcotics, both natural and synthetic, that bind to opioid receptors in the brain (including antagonists) [5]. Opiates are alkaloid compounds naturally found in the opium poppy plant Papaver somniferum [6]

Tramadol is centrally acting opioid, many physicians use it for moderate and severe pain in adult because it's thought to have minimal risk for addiction compared to other opioid. So, it's widely spread between patients to relief their pain, some patient continue to use tramadol to achieve sense of well being that's why it is the third opioid most frequently to be abused [7] .

Because of the widespread of psychiatric disorder and substance use and their associated disabilities, accurate comprehension of their co morbidity is very important for prevention and treatment especially among young adult as this 
age group disabilities represent a burden on any society [8].

Anxiety normally is an adaptive mechanism that signals a potentially harmful internal or external change and thereby enables individuals to avoid harm or to cope with stress. When anxiety occurs for seemingly no reason or in an exaggerated manner in response to relatively innocuous stimuli and disrupts a person's life, an anxiety disorder may be diagnosed. Anxiety disorder is a pattern of several disorders that are characterized by a feeling of fear, dread, or apprehension that arises without a clear or appropriate cause [9] .

Social phobia is continuous fear of one or more social situation such as eating in front of others in which the patient is exposed to unfamiliar people. The patient fears that he or she will act in a manner (or show anxiety symptoms including diaphoresis, apnea, tremors, tachycardia, and nausea) that will be disturbing or shameful, typically lasting 6 or more months [10].

Now who start first? Social phobia or drug use. Drug use may increase intensity of social phobia and at the same time social phobia is a motivating factor of drug use. So, if we recognize this point this will help not only in treatment but also in decrease relapse of drug use. For example, patient with drug use because he/she is already has social phobia before is at high risk of reuse drug more than patient without social phobia [11].

Aim of the work: To identify the relationship between social phobia and tramadol and opioid use, and if it has a role in starting drug use.

\section{Subjects and Methods}

This study was carried out at Psychiatry, Neurology and Neuro-Surgery Center, Tanta University on 103 drug user through the period from from 1 st of June to the end of December 2017. A sequencial study design was used in the current study. The participants were classified into 3 groups: Tramadol users which included 40 patients aged between 18 and 50 years and had positive urine test for Tramadol only. Opioid users which included 25 patients aged between 18 and 50 years and had positive urine test for Opioid only. Combined drug users (Tramadol and Opioid) included 38 patients aged between 18 and 50 years and had positive urine test for both Tramadol and Opioid. Patients with other drug use disorder were excluded as well as patients who have serious systemic disorders, significant neurological disorder (e.g. cerebrovascular stroke, epilepsy, Parkinsonism), learning disabilities and mental retardation and pervasive developmental disorders. Assessment of demographic variables including age, gender, occupation, marital status and type of drug used. Psychiatric history and examination through Structured Clinical Interview for DSM5 Disorders (SCID-5-CV) [12] Physical examination was done for all subjects included in the study. Drug screen in urine which is done for 5 major drug abused: Cannabis, Opiate, Tramadol, Barbiturates and Benzodiazepines. Psychometric tests: Hamilton Depression Rating Scale (HAM-D) [13], Hamilton Anxiety Rating Scale (HAM-A) [14], Raulin and Wee scale for social phobia [15] and Addiction Severity Index (ASI) [16].

\section{Results}

The present study was carried on 103 Egyptian subjects selected from outpatient clinic and inpatients admitted in Tanta University Psychiatry, Neurology \& Neurosurgery Center. (Range of age 15-50 years, 77 male and 26 female) to estimate level of social phopia, depression and anxiety among tramadol and/or opioid users and if it has a role in starting drug use or relapse after withdrawal.

Table (1): Characteristics of studied patients.

\begin{tabular}{|c|c|c|}
\hline Correlations & $\mathrm{N}$ & $\%$ \\
\hline $\begin{array}{l}\text { Age groups: } \\
\text { <30 years } \\
\text { 30-40 years } \\
>40 \text { years } \\
\text { Range } \\
\text { Mean } \pm \mathrm{SD}\end{array}$ & $\begin{array}{l}48 \\
38 \\
17 \\
\\
31\end{array}$ & $\begin{array}{r}46.60 \\
36.89 \\
16.50 \\
50 \\
=8.178\end{array}$ \\
\hline $\begin{array}{l}\text { Gender: } \\
\text { Male } \\
\text { Female }\end{array}$ & $\begin{array}{l}77 \\
26\end{array}$ & $\begin{array}{l}74.76 \\
25.24\end{array}$ \\
\hline $\begin{array}{l}\text { Occupation: } \\
\text { Non employed } \\
\text { Employed }\end{array}$ & $\begin{array}{l}31 \\
72\end{array}$ & $\begin{array}{l}30.10 \\
69.90\end{array}$ \\
\hline $\begin{array}{l}\text { Marital status: } \\
\text { Single } \\
\text { Married } \\
\text { Divorced }\end{array}$ & $\begin{array}{l}36 \\
56 \\
11\end{array}$ & $\begin{array}{l}34.95 \\
54.37 \\
10.68\end{array}$ \\
\hline $\begin{array}{l}\text { Drug: } \\
\quad \text { Tramadol } \\
\text { Opioid } \\
\text { Both }\end{array}$ & $\begin{array}{l}40 \\
25 \\
38\end{array}$ & $\begin{array}{l}38.83 \\
24.27 \\
36.89\end{array}$ \\
\hline
\end{tabular}

Table (1) the sample of this study consisted of 103 drug users aged from 18-50 years. They were distributed as follows: About $74.76 \%$ of the studied sample were males and $48.4 \%$ were females. As regard marital status, majority of them were married $54.37 \%$. 


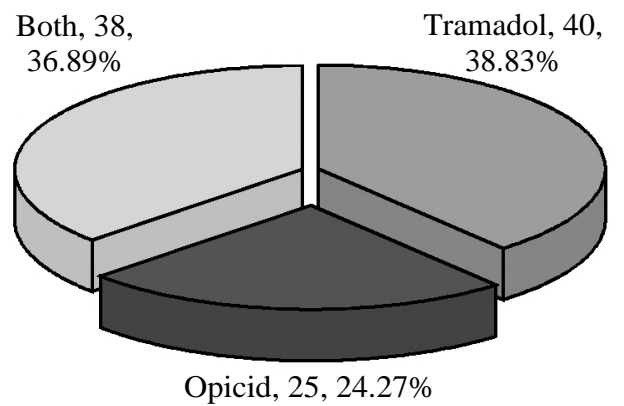

Fig. (1): Distribution of studied patients by drug abuse.

Fig. (1) it was found that majority of patients were tramadol users followed by users of both tramadol and opioid with percentage $38.83 \%$ and $36.89 \%$ respectively.

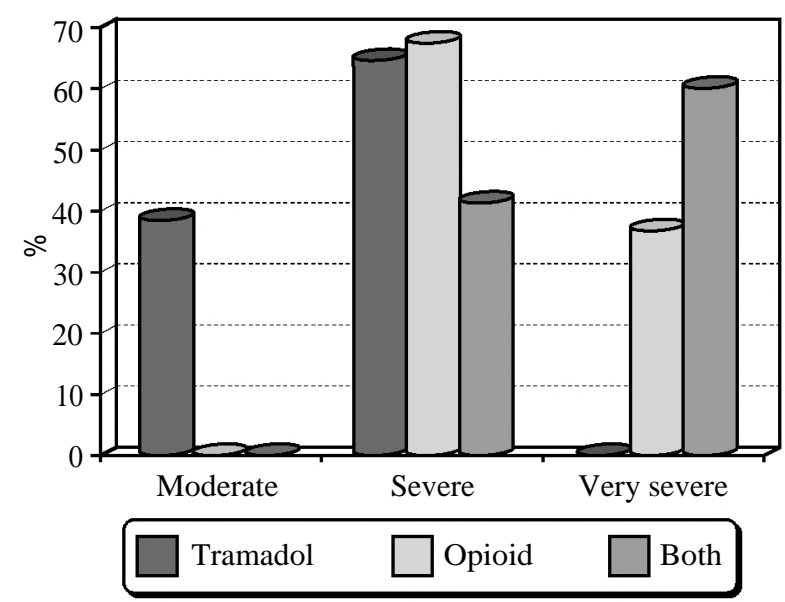

Fig. (2): Distribution of studied patients in relation to drug use disorder and drug use severity index.

Fig. (2): Addiction severity index lite was severe among $65 \%$ of tramadol patients and $68 \%$ of opioid users, while the index was very severe among $60.5 \%$ of users of combined tramadol and opioid.

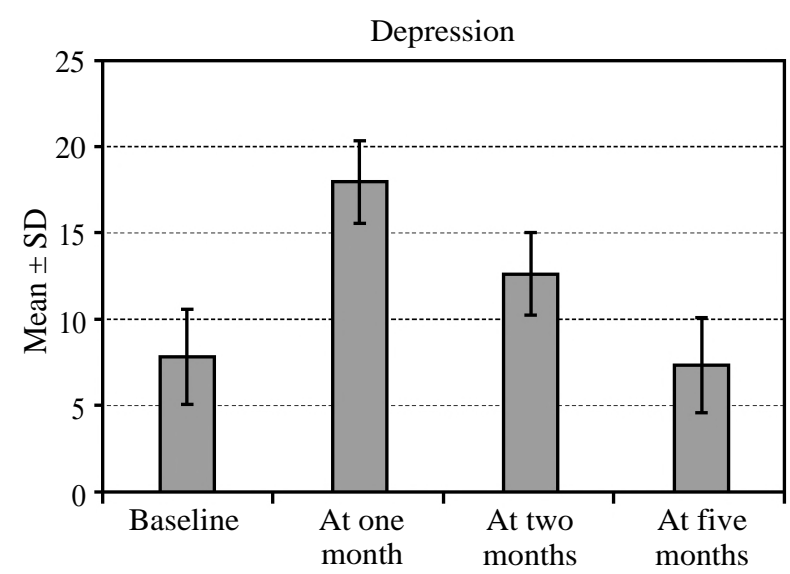

Fig. (3): Comparison of depression among tramadol users at different periods of follow-up.

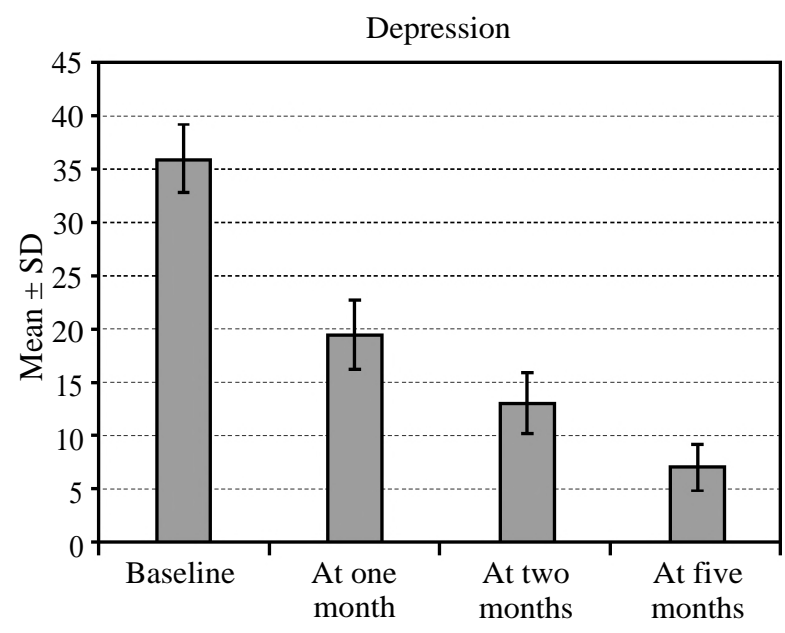

Fig. (4): Comparison of depression among opium users at different periods of follow-up.

Figs. $(3,4)$ level of depression among tramadol users at base line and after withdrawal using Hamilton depression rating scale. Maximum level of depression was after one month of withdrawal with range 14-23 and mean \pm SD $17.90 \pm 2.35$. While maximum level of depression among opioid users was at base line with range $27-44$ and mean \pm SD $35.68 \pm 3.16$ then decreased gradually to the lowest range after five months with range 4-12 and mean \pm SD $6.92 \pm 2.14$.

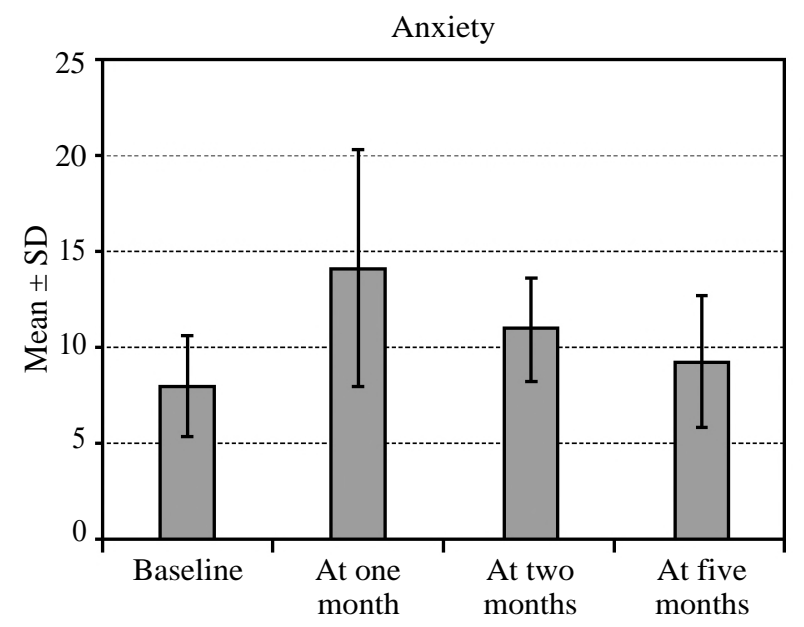

Fig. (5): Comparison of anxiety among tramadol users at different periods of follow-up.

Fig. (5): Level of anxiety among tramadol users at base line and after withdrawal using Hamilton anxiety rating scale. Anxiety had minimal variation all over the study among tramadol users with maximum range 5-24 with mean \pm SD $14.00 \pm 6.11$ after one month of withdrawal. While maximum range of anxiety was $15-35$ with mean \pm SD $16.84 \pm$ 5.02 after one month of withdrawal. 


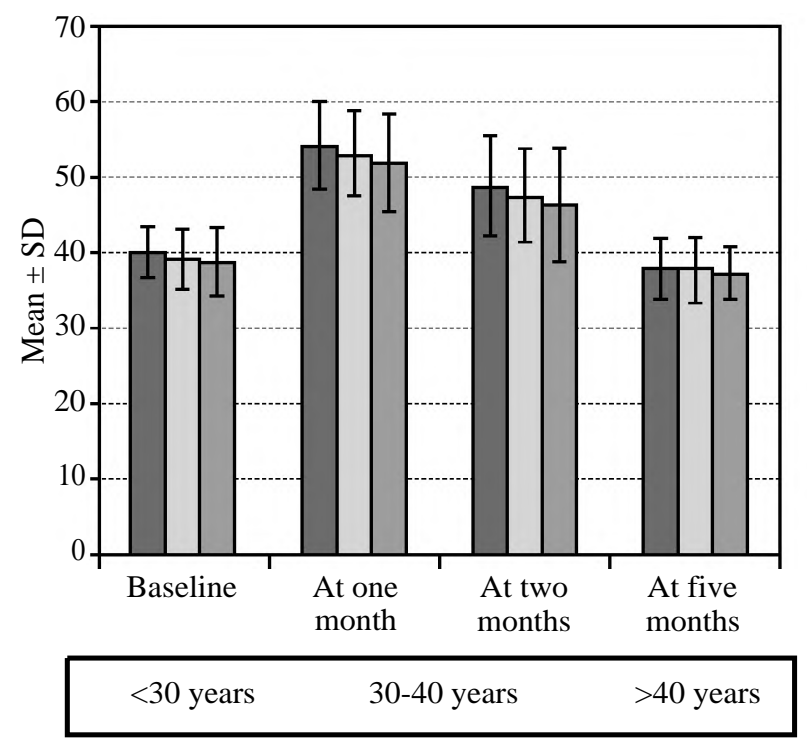

Fig. (6): Relationship of social phobia to age at different period of follow-up after drug withdrawal.

Fig. (6): Demonstrates relationship between social phobia and age which was statically not significant however younger age group $<30$ years had higher level of social phobia throughout the study.

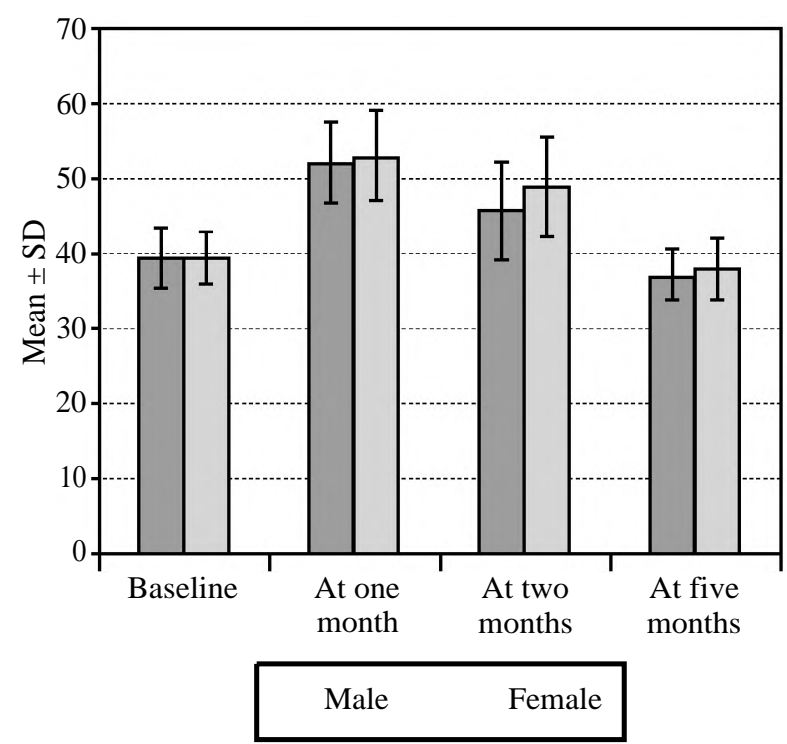

Fig. (7): Relationship of social phobia to gender at different period of follow-up after drug withdrawal.

Fig. (7): Demonstrates relationship between social phobia and gender where females had higher level of social phobia throughout the study and was statically significant after two months of withdrawal with range $36-60$ and mean \pm SD 48.792 \pm 6.779 .

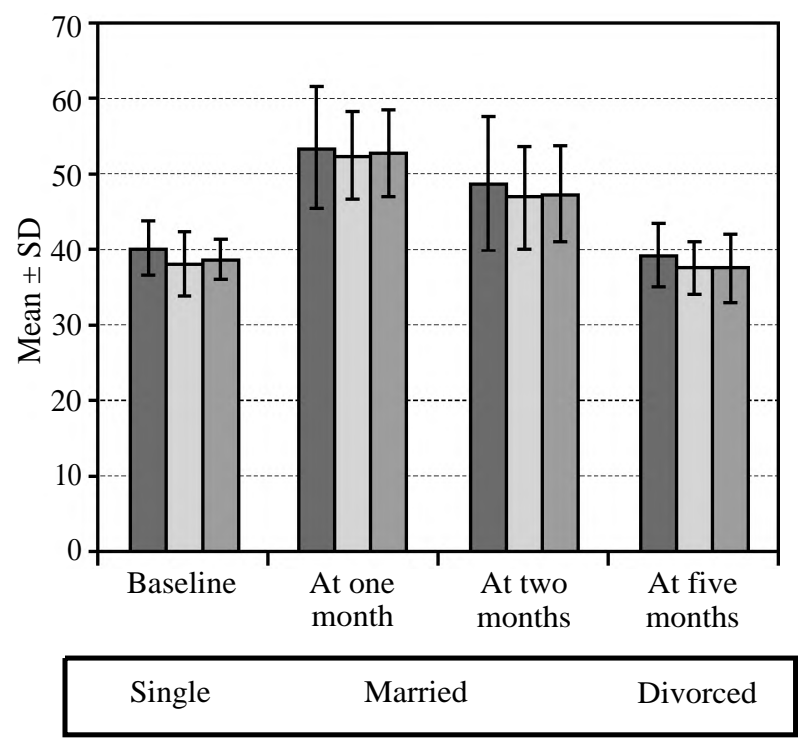

Fig. (8): Relationship of social phobia to marital status at different period of follow-up after drug withdrawal.

Fig. (8): Demonstrates relationship between social phobia and marital status where single users had higher level of social phobia throughout the study and was statically significant at base line with range $36-45$ and mean \pm SD 38.727 \pm 2.760 .

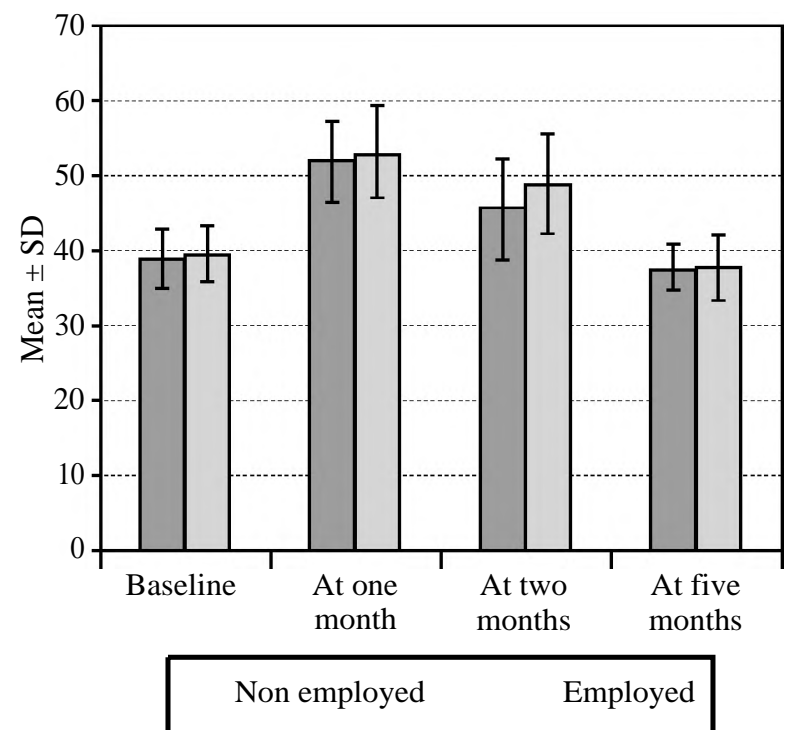

Fig. (9): Relationship of social phobia to occupation at different period of follow-up after drug withdrawal.

Fig. (9): Demonstrates relationship between social phobia and occupation where employed users had the same level of social phobia throughout the study and was statically significant only after two month of withdrawal among employed users with range $36-60$ and mean \pm SD $48.944 \pm 6.680$. 


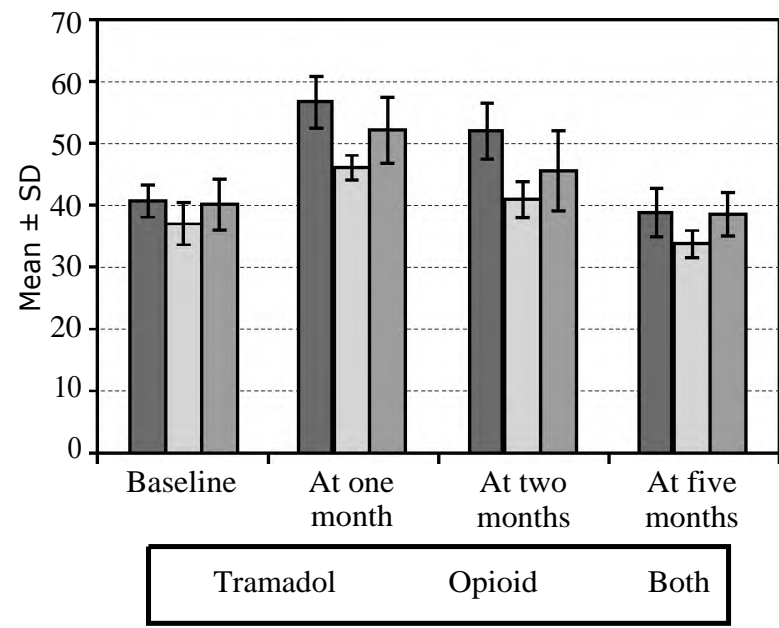

Fig. (10): Relationship of social phobia to drug use at different period of follow-up after drug withdrawal.

Fig. (10): Demonstrates relation between social phobia and type of drug used which was obviously more among tramadol users throughout the study followed by combined drug (tramadol and opioid) users and opioid users respectively.

Table (2): Correlation between social phobia to severity of drug use at different period of follow-up after drug withdrawal using addiction severity index.

\begin{tabular}{lcc}
\hline \multicolumn{3}{c}{ Correlations } \\
\cline { 2 - 3 } & \multicolumn{2}{c}{ ASI } \\
\cline { 2 - 3 } & $r$ & $p$-value \\
\hline Baseline & 0.344 & $0.001^{*}$ \\
At one month & 0.274 & $0.028^{*}$ \\
At two months & 0.131 & 0.187 \\
At five months & 0.059 & 0.557 \\
\hline
\end{tabular}

Table (2) demonstrates the relation between social phobia and severity of addiction where social phobia was directly proportional to severity of drug use and was significant at base line and after one month of withdrawal with $p$-value 0.001 and 0.028 respectively.

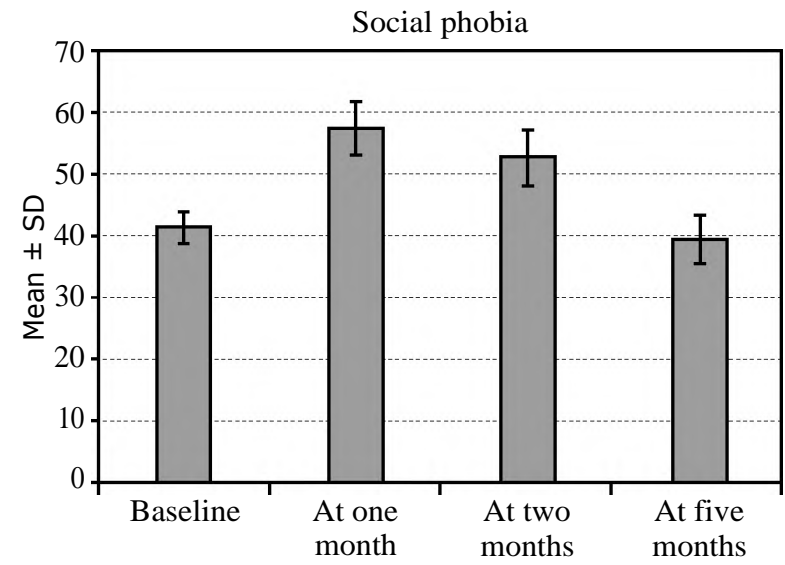

Fig. (11): Comparison of social phobia among tramadol users at different periods of follow-up.
Fig. (11): Demonstrates level of social phobia among tramadol users at base line and after withdrawal using Raulin and Wee scale for social phobia. Tramadol users had high range of social phobia throughout the study which obviously increased after one month of withdrawal with range 49-63 and mean \pm SD 57.000 \pm 4.297 .

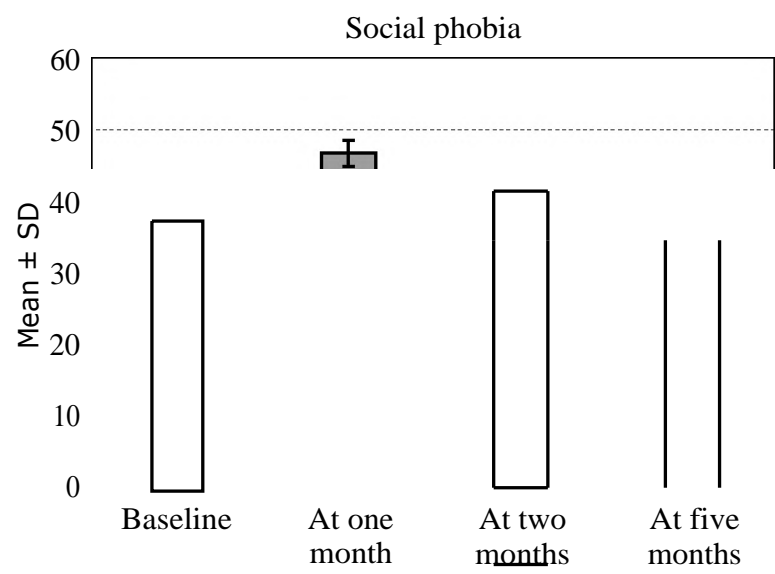

Fig. (12): Comparison of social phobia among opium users at different periods of follow-up.

Fig. (12): Demonstrates level of social phobia among opioid users at base line and after withdrawal using Raulin and Wee scale for social phobia. Opioid users had high range of social phobia throughout the study with maximum level of social phobia was after one month of withdrawal with range 44-50 and mean \pm SD $46.400 \pm 1.958$.

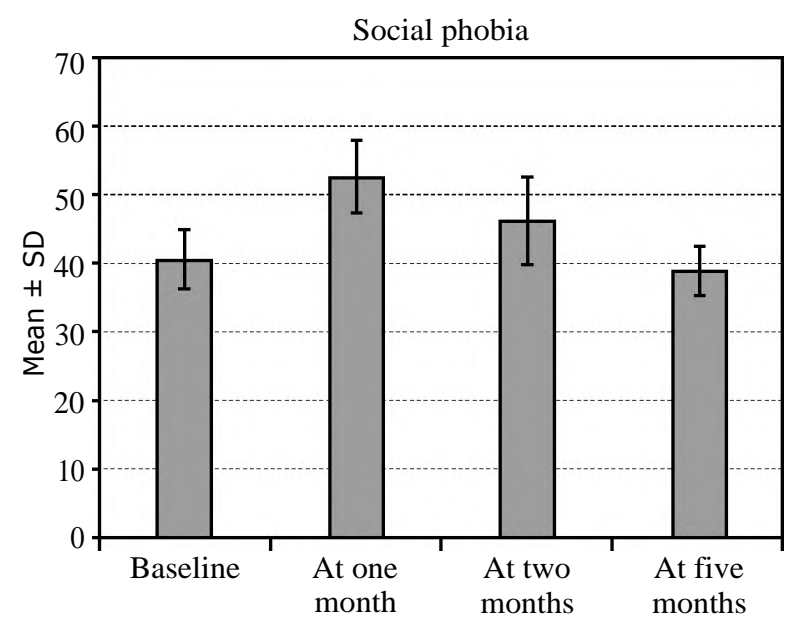

Fig. (13): Comparison of social phobia among combined (tramadol and opium) users at different periods of follow-up.

Fig. (13): Demonstrates level of social phobia among combined (tramadol and opioid) drug users at base line and after withdrawal using Raulin and Wee scale for social phobia. Both drug users had high range of social phobia throughout the study 
with maximum level of social phobia was after one month phobia was after one month of withdrawal with range 38-62 and 36-56 mean \pm SD $52.21 \pm 5.87$.

Table (3) demonstrates relationship between symptoms of social phobia and depressive symptoms which was directly proportional thoughout the study where social phobia was more prevalent among depressed subjects. It was significant with weak correlation at base line and strong correlation at one months after withdrawal.

Table (4) demonstrates relationship between symptoms of social phobia and anxiety symptoms which was directly proportional thoughout the study where all subjects with anxiety symptoms had higher level of social phobia. Social phobia had significant correlation with anxiety at base line, one and two months with $p$-value $<0.001$.

Table (3): Correlation between symptoms of social phobia to depressive symptoms at different period of follow-up after drug withdrawal.

\begin{tabular}{|c|c|c|c|c|c|c|c|c|}
\hline & \multicolumn{8}{|c|}{ Correlations } \\
\hline & \multicolumn{2}{|c|}{$\begin{array}{l}\text { Social phobia } \\
\text { at baseline }\end{array}$} & \multicolumn{2}{|c|}{$\begin{array}{l}\text { Social phobia } \\
\text { at one month }\end{array}$} & \multicolumn{2}{|c|}{$\begin{array}{l}\text { Social phobia } \\
\text { at two months }\end{array}$} & \multicolumn{2}{|c|}{$\begin{array}{r}\text { Social phobia } \\
\text { at five months }\end{array}$} \\
\hline & $r$ & $p$-value & $r$ & $p$-value & $r$ & $p$-value & $r$ & $p$-value \\
\hline Depression at baseline & 0.344 & $<0.001 *$ & & & & & & \\
\hline Depression at one month & & & 0.454 & $<0.001 *$ & & & & \\
\hline Depression at two months & & & & & 0.019 & 0.847 & & \\
\hline Depression at five months & & & & & & & 0.026 & 0.798 \\
\hline
\end{tabular}

Table (4): Correlation between symptoms of social phobia to anxiety symptoms at different period of follow-up after drug withdrawal.

\begin{tabular}{|c|c|c|c|c|c|c|c|c|}
\hline & \multicolumn{8}{|c|}{ Correlations } \\
\hline & \multicolumn{2}{|c|}{ Social phobia 0} & \multicolumn{2}{|c|}{ Social phobia $1 \mathrm{~S}$} & \multicolumn{4}{|c|}{ Social phobia 2 Social phobia 5} \\
\hline & $r$ & $p$-value & $r$ & $p$-value & $r$ & $p$-value & $r$ & $p$-value \\
\hline $\begin{array}{l}\text { Anxiety at baseline } \\
\text { Anxiety at one month } \\
\text { Anxiety at two months }\end{array}$ & 0.376 & $<0.001 *$ & 0.388 & $<0.001 *$ & 0.251 & $0.011 *$ & & \\
\hline Anxiety at five months & & & & & & & 0.084 & 0.396 \\
\hline
\end{tabular}

\section{Discussion}

Age:

The mean age of the studied subjects was $31.50+8.17$ years old. This young age of subjects was in agreement with the results of United Nation Office of Drug and Crime that found that substance abuse was also more prevalent among young people [15].

The present study agreed also with the results of the Egyptian National Addiction Survey which the General Secretariat of Mental Health performed since 1996 that showed decreases in the mean age of onset of drug use and substance abuse was the highest among the age 20-45 years than other age groups [16].

Age difference in the current study was not consistent with the study of Daniel Feingold et al., who found that more cases were between 45-64
[17]. This may be due to older age group included in the study.

\section{Gender:}

In this study opioid and/or tramdol use disorder was more in males (77) than females (26) with percentage $74.8 \%$ male and $25.2 \%$ female.

This was in agreement with the results of an Egyptian study carried out by Hosam El-Sawy et al., in Tanta University Hospital in 2010 who studied possible gender differences in the ways of first exposure to drugs, in their risks of abuse, and the pattern of drug dependence and they found that males started drug abuse earlier in age than females with longer duration of addiction. Single males were more vulnerable to abuse than females [18]

Also this result was in agreement with the result of Loffredo, CA et al., who studied prevalence and correlates of substance use by Egyptian school 
youth where $72 \%$ percent of participants were male [20]. In another study done by M. Wasify, 2011 the majority of participants were Male [19].

This was also in agreement with the results of the Egyptian National Addiction Survey that showed that substance abuse was more common in males than in females [21]. Also gender difference was in agreement with the result of Jeanette $M$. Tetrault et al., who found that Women were significantly less likely than men to have past year non medical use of prescription opioids [22].

\section{Marital status:}

In the present study; opioid and/or tramadol use was more prevalent in married and single than divorced subjects. This was in agreement with the study of Daniel Feingold et al., who studied the association between severity of depression and prescription opioid misuse and founded that more than $50 \%$ of opioid users were married [23].

\section{Depression:}

The results of this study was significant regarding depression among tramadol and/or opioid users. It was clearly significant that tramadol has antidepressant effect as $p$-value was 0.001 while long term use of opioid lead to significant depression that decreased after withdrawal as $p$-value was 0.001 . On the other hand users of both drugs had lesser degree of depression with $p$-value 0.001 .

In a study done by M.M. Rizk et al., who studied frequency and factors associated with depression in subjects with tramadol use disorder and founded that most of tramadol users had mild depression [24]. This was in agreement with lower range of depression among tramadol users (3-14) and mean $\pm \mathrm{SD} 7.83 \pm 2.70$ and this level increased after withdrawal.

In a study done by Jamshid Ahmadi who founded that both tramadol and opioid users has mild level depression [25]. The range of depression among tramadol and opioid users of the current study was $14-25$ with mean \pm SD $18.55 \pm 3.00$.

In another study done by Reeves et al., founded that depression increased after tramadol withdrawal and this was also in agreement with the increased range of depression at one month after tramadol withdrawal with range 14-23 and mean \pm SD 17.90 \pm 2.35 [26].

Level of depression in the current study was not consistent with the study of Andrew et al., in Australian general population which was only $6 \%$ [27]. Also rate of depression was not consistent with the result of Ahmed B et al., who founded depression in only $30 \%$ of opioid users. Although depression was severe in majority of them [28].

Anxiety:

The result of this study indicated that anxiety disorders may contribute to the onset of substance use disorder. It was significant among tramadol and/or opioid users as $p$-value was 0.001 . Anxiety level slighty differ along the duration of the study with minimal variation from no anxiety to mild anxiety.

Daniel Feingold et al., who studied the association between severity of depression and prescription opioid misuse, had founded that most of the studied subject had no anxiety and fewer subjects had mild anxiety [17]. This was with aggrement with the recent study as anxiety had minimal variation all over the study. Total range was 3-24 with with significant $p$-value 0.001 .

In another study; Zimmermann et al., who studied prevalence of social phobia in a clinical sample of drug dependent patients. It was founded that $20 \%$ of the subjects in his study had generalized anxiety disorder [29]. This result of was also in agreement with low anxiety level at base line with range 9-24 and mean \pm SD 16.84 5.02 .

The result of this study agreed also with study of RK McHugh et al., who founded that opioid withdrawal worsen anxiety, resulting in a cycle of chronic anxiety and opioid use that is extremely difficult to interrupt [17]. This result of was in agreement with low anxiety level at base line with range 9-24 and mean \pm SD $16.84 \pm 5.02$ that increased at one month after withdrawal with range

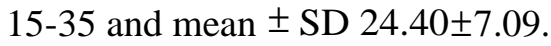

This result also agreed with Ahmad et al., who studied psychiatric comorbidity in substance use disorder who founded that psychiatric co-morbidity among opioid users was prevalent and associated with $4 \%$ prevalence of anxiety in the studied group and $60 \%$ of them were tramadol users [28]. This was in agreement with the recent study as tramadol users had various degree of anxiety throughout the study with significant $p$-value 0.001 .

Another study done by M.C. Rodríguez-Llera et al., who studied psychiatric comorbidity in young heroin users had founded that $40 \%$ of the users had generalized anxiety disorder [30]. This was in agreement with the results of the recent study as nearly all patients had anxiety symptoms that had varying range throughout the study. 
Also Bridget F. Grant et al., had found that there is a strong association between generalized anxiety disorder and drug use and only a few individuals with mood or anxiety disorders were classified as having only substance-induced disorders. Associations between most substance use disorders and independent mood and anxiety disorders were positive and significant [31]. This was in agreement with the results of the recent study as nearly all patients had co morbid depressive and anxiety symptoms.

\section{Social phobia:}

The result of the current study was significant among tramadol and/or opioid users as $p$-value was 0.001 . The result of this study demonstrated that most users started using drugs as an escape from their phobia. This can be approved by this study as users of tramadol and/or opioid were severely affected after withdrawal especially users with tramadol.

This was in agreement with the study of William et al., in his study of non-medical use, use disorder and dependence on prescription opioids among U.S. adults on subjects aging 18 year and more who founded that past year drug use was due to many psychiatric problems especially phobias [32]

The result of a study done by Goodwin et al., who investigated the relation between specific anxiety disorders and substance dependence and founded that substance dependence temporally precedes several anxiety disorders and social phobia was worsened with specific drug withdrawal [1] This was in agreement with the recent study where level of social phobia was directly proportional to level of anxiety, also social phobia obviously increased after drug withdrawal especially with tramadol from range $32-45$ to $47-63$ and from mean \pm SD $37.15 \pm 3.65$ to $56.93 \pm 4.43$.

In another study done by Mariette J. Chartier who studied comorbidity of social phobia with other psychiatric diseases and founded that $31 \%$ of socially phobic subjects had comorbid anxiety and $80 \%$ had comorbid drug use disorder [34]. This was in agreement with the recent study where there was a strong correlation between social phobia and anxiety that was directly proportional throughout the study with significant $p$-value $<0.001$ at base line, one and two months.

This also was in agreement with Zimmermann et al., who studied prevalence of social phobia in a clinical sample of drug users and founded that $40 \%$ of the subjects in his study had social phobia [29]. In comparison to the recent study; $50 \%$ of tramadol and/or opioid users had social phobia at base line (before withdrawal). Also gender difference emerged in the severity of fear, females reporting significantly greater social phobia than males was in agreement with the recent study as female had higher range than males throughout the study which was significant at two month with $p$-value 0.039 .

In another study done by Mark Zimmerman for screening for psychiatric disorders in one thousand outpatients with substance use disorders, $27.8 \%$ of patients were having social phobia which perceeded only by incidence of depression (49\%) among opioid users [35]. This was in agreement of the recent study where social phobia had been directly proportional with depression with nearly $50 \%$ of users had depressive symptoms most of them were opioid users.

Also Fiona L. Shand et al., who assessed levels of social anxiety and identified its predictors in an opioid dependent sample had founded that cases with opioid use disorder had higher scores than controls on mood, anxiety and social phobia [36] This result was in agreement with the relation between social phobia and drug use. Also social phobia had higher prevalence among depressed subjects which was significant with high correlation at one month after withdrawal with $p$-value 0.001 , while social phobia had a direct proportion with anxiety which was significant with high correlation at base line, one and two months with $p$-value 0.001 .

Also comorbidity of social phobia with other psychiatric diseases was observed by a study done by Renee $\mathrm{D}$ et al., who founded that $30 \%$ of subjects had first onset anxiety disorder [1]. This was in agreement with the recent study as there was strong correlation between anxiety and social phobia throughout the study with significant $p$-value $<0.001$.

On the other hand; Kevin P. Conwy et al., in his study of life time co morbidity of mood and anxiety and specific drug use disorder, had founded that the prevalences of any lifetime mood and anxiety disorders among drug users were $40.9 \%$ and $29.9 \%$, respectively. Major depression was the most prevalent $(29.2 \%-59.8 \%)$ and one of the strongest associations were observed between depression and opioid [37] that result agrees with prevalence of depressive symptoms among 50\% of the subjects included in the current study and most of depressive symptoms were among opioid users with range $27-44$ and mean $35.68 \pm 3.16$ at base line with $p$-value 0.001 . 
Another study was done by Kevin P. Conwy et al., to illustrate association of lifetime mental disorders and subsequent ilicit drug use disorder were highest among adolescents with prior anxiety disorders with $20 \%$ which agree with the result of the recent study where most of the subject included were younger than 30 years with significant varying degrees of anxiety throughout the study with $p$ value 0.001 [38]

In addition; a study done by Sareen $\mathrm{J}$ et al., to the relationship between anxiety disorders and lifetime use of amphetamines, cocaine, hallucinogens and heroin had founded that anxiety and social phobia diagnosis was significantly associated with lifetime heroin use in the US survey and clinicians and researchers need to be aware of the relationship between anxiety disorders and illicit drug use. This was in agreement with our study where there was a strong association between anxiety, social phobia and drug use disorder which was significant with high correlation at base line, one and two months with $p$-value $0.001 \quad$ [39]

This result was also in agreement with the study of Battjes et al., who demonstrated that $63 \%$ of drug users were socially phobic [33]. Also in a study done by John Canton et al., to evaluate optimal treatment of social phobia there was strong association between drug use and social phobia and $80 \%$ of drug users had prior onset of social phobia that appear obviously at one month where nearly all subjects had high range of social phobia with significant $p$-value 0.001 [40]

Also epidemiology and natural course of social fears and social phobia demonstrated by Wittchen et al., had reported elevated rates of comorbidity for social phobia. It has been estimated that 50$80 \%$ of clinical patients with social phobia have at least one other mental disorder typically other anxiety disorders, depression or substance use disorders. High prevalence of comorbidity with depressive disorders, with many individuals suffering from social phobia agreed with the correlation between symptoms of depression and social phobia throughout the recent study with high correlation and significant $p$-value 0.001 at one and two months after withdrawal [41]

In another study done by Ingmar H.A. Franken et al., for screening and diagnosis of anxiety and mood disorders in a sample of 116 patient with substance use disorder, $90 \%$ of them were tramadol and opioid users. It was founded that the majority of the subjects $(69.8 \%)$ had a lifetime anxiety and social phobia had the highest prevalence $(53.2 \%)$ [42]. This was in agreement with the recent study where most of drug users had co morbid anxiety and social phobia with significant strong correlation especially at base line, one and two months with $p$-value $<0.001$.

In another study done by William C. Becker et al., who studied non-medical use, use disorder and dependence on sedatives and tranquilizers among U.S. adults aging 18 years old and above, there was a strong evidence that recent onset of nonmedical use of opioid and tramadol play an important role in alleviating symptoms of panic and social phobia in addition, they were more likely to be older and unmarried [43]. This was in agreement with the recent study as drug users had lower levels of anxiety and social phobia at base line (average range 3-24 and 37-45 respectively) with significant increase in range at one month after withdrawal (average range 11-35 and 45-63 respectively).

Social phobia were common among young adults, single and females and obviously affects their life and their relation with others over a long period of time which make them a heavy burden on society as social phobia make them seeking drugs and when drug use treated they may realapse multiple times after treatment.

Social phobia was a catalyst factor for drug use as drug users can resist their fears when using drugs. This was approved obviously by high levels of social phobia that appeared after drug withdrawal all over the stages of the study that did't return to normal levels after 5 months of withdrawal.

Most of drug users experience high level of social phobia after drug withdrawal with co morbid anxiety and/or depressive symptoms with significant $p$-value at various stages of the study. This can explain why most drug users relapse after short period of time after detoxification if other psychiatric co morbidity not properly treated.

Anti depressant, anxiolytic and cognitive behavioral therapy should be put in mind when treating social phobia co morbid with drug use disorder especially tramadol as it plays a vital role in reducing symptoms of social phobia, so proper treatment of social phobia will absolutely decrease recurrence of drug use disorder.

Finally; clinicians and researchers need to be aware of the relationship between social phobia, anxiety, depression and illicit drug use. Treatment of primary mental disorders especially those mentioned above is likely to be an important target for the prevention of secondary substance use disorders. 


\section{Limitations:}

The main limitation in this study was combined cannabis use disorder which made the number of patients less than predicted. Also little number of female patients needs more studies to be more accurate.

\section{Conclusion:}

From this study the following could be concluded: Tramadol withdrawal leads to significant social phobia and depression that should be properly treated. Opioid use disorder lead to significant depression especially with longer duration of drug use. Subjects with opioid use disorder significantly suffer from depression more than subjects with tramadol use only or both drugs users. Opioid had anxiolytic effect similar to the effect of tramadol. Opioid withdrawal leads to social phobia and anxiety less than that was observed in Tramadol.

\section{Acknowledgments:}

This research was carried out without funding. We thank the cooperative persons, who accepted to participate in this study and gave of their time to finish the interview voluntarily and their care givers.

\section{Conflicts of interest: No conflicts of interest declared.}

Authors' contributions: All authors had equal role in design, work, statistical analysis and manuscript writing. All authors have approved the final article work.

\section{References}

1- GOODWIN R.D. and D.J. STEIN: Anxiety disorders and drug dependence: Evidence on sequence and specificity among adults. Psychiatry and clinical neurosciences, 67 (3): p. 167-73, 2013

2- COMPTON W.M., et al.: Psychiatric disorders among drug dependent subjects: Are they primary or secondary? American Journal on Addictions, 9 (2): p. 126-34, 2000.

3- TOMKINS S.S.: Psychological model for smoking behavior. American Journal of Public Health and the Nations Health, 56 (12-Suppl): p. 17-20, 1966.

4- CAULKINS J.P. and P. REUTER: Dealing more effectively and humanely with illegal drugs. Crime and justice, 46 (1): p. 95-158, 2017.

5- ROYSTON D. and H.C. HEMMINGS: Physiology and Pharmacology for Anesthesia: Foundations and Clinical Application: Expert Consult-Online and Print, 2013.

6- TORRENS M., et al.: Opioid addiction: Short-and longacting opioids. Textbook of Addiction Treatment: International Perspectives, p. 467-500, 2015.

7- NAIDU R.K. and T.M. PHAM: Pain Management, in Basic Clinical Anesthesia, Springer. p. 265-96, 2015.
8- RICHMAN J.A., et al.: Workplace harassment and the self-medication of distress: A conceptual model and case illustrations. Contemporary Drug Problems, 24 (1): p. 179-200, 1997.

9- ABRAMOWITZ J.S., B.J. DEACON and S.P. WHITESIDE: Exposure therapy for anxiety: Principles and practice: Guilford Press, 2011.

10- ASSOCIATION A.P.: Diagnostic and statistical manual of mental disorders (DSM-5®): American Psychiatric Pub, 2013.

11- RANDALL C.L., S. THOMAS, and A.K. THEVOS Concurrent alcoholism and social anxiety disorder: A first step toward developing effective treatments. Alcoholism: Clinical and experimental research, 25 (2): p. 210-20, 2001.

12-FIRST M.B. and J.B. WILLIAMS: SCID-5-CV: Structured Clinical Interview for DSM-5 Disorders: Clinician Version: American Psychiatric Association Publishing, 2016.

13- HAMILTON M.: A rating scale for depression. Journal of neurology, neurosurgery, and psychiatry, 23 (1): p. 56, 1960.

14- HAMILTON M.: The assessment of anxiety states by rating. British journal of medical psychology, 32 (1): p. $50-5,1959$.

15- Drugs U.N.O.O. and Crime, World drug report 2010. United Nations Publications, 2010.

16- HAMDI E., et al.: Sociodemographic indicators for substance use and abuse in Egypt. J. Addiction Prevention, 4 (1): p. 8, 2016.

17- FEINGOLD D., et al.: The association between severity of depression and prescription opioid misuse among chronic pain patients with and without anxiety: A crosssectional study. Journal of affective disorders, 235: p. 293-302, 2018.

18- EL-SAWY H., M. ABDEL HAY, and A. BADAWY: Gender differences in risks and pattern of drug abuse in Egypt. Egypt J. Psychiat. Neurosurg., 47: p. 413-8, 2010.

19- SHARMA I., T. JHA, and P.K. KAUNDAL: Assessment of the profile of psychiatric manifestations in cannabis users: A cross sectional study. National Journal of Medical Research, 6 (1): p. 58-61, 2016.

20- LOFFREDO C.A., et al.: Substance Use by Egyptian Youth: Current Patterns and Potential Avenues for Prevention. Substance Use \& Misuse, 50 (5): p. 609-18, 2015.

21- EL-WASIFY M.A., et al.: The Prevalence and Correlates of Common Mental Disorders in Dakahlia Governorate (Egypt). Egyptian Journal of Neurology, Psychiatry \& Neurosurgery, 48 (4), 2011.

22- TETRAULT J.M., et al.: Gender and non-medical use of prescription opioids: Results from a national US survey. Addiction, 103 (2): p. 258-68, 2008.

23- DIAMOND A.: Executive functions. Annual review of psychology, 64: p. 135-68, 2013.

24- RIZK M., et al.: P. 6. d. 011 Frequency and factors associated with depression in subjects with tramadol abuse. European Neuropsychopharmacology, 25: p. S617, 2015. 
25- AHMADI J.: Tramadol Dependency Treatment: A New Approach. Psychiatry, 15: p. 247-8, 2015.

26- REEVES R.R. and S.K. COX: Similar effects of tramadol and venlafaxine in major depressive disorder. Southern medical journal, 101 (2): p. 193-5, 2008.

27- ANDREWS G., et al.: The mental health of Australians. Mental Health Branch, Commonwealth Department of Health and Aged Care Canberra, 1999.

28- AHMAD B., K. MUFTI, and S. FAROOQ: Psychiatric comorbidity in substance abuse (opioids). JPMA. The Journal of the Pakistan Medical Association, 51 (5): p. 183-6, 2001.

29- ZIMMERMANN G., et al.: Prevalence of social phobia in a clinical sample of drug dependent patients. Journal of affective disorders, 83 (1): p. 83-7, 2004.

30- RODRIGUEZ-LLERA M., et al.: Psychiatric comorbidity in young heroin users. Drug and Alcohol Dependence, 84 (1): p. 48-55, 2006.

31- GRANT B.F., et al.: Prevalence and co-occurrence of substance use disorders and independentmood and anxiety disorders: Results from the national epidemiologic survey on alcohol and relatedconditions. Archives of general psychiatry, 61 (8): p. 807-16, 2004.

32- BECKER W.C., et al.: Non-medical use, abuse and dependence on prescription opioids among US adults: Psychiatric, medical and substance use correlates. Drug and alcohol dependence, 94 (1): p. 38-47, 2008.

33- BATTJES R.: Etiology of Drug Abuse: Implication for prevention. National Institute on drug Abuse Research Monograph, (56): p. 193-35.

34- CHARTIER M.J., J.R. WALKER, and M.B. STEIN: Considering comorbidity in social phobia. Social psychiatry and psychiatric epidemiology, 38 (12): p. 728-34, 2003.
35- ZIMMERMAN M., et al.: Screening for psychiatric disorders in outpatients with DSM-IV substance use disorders. Journal of Substance Abuse Treatment, 26 (3): p. 181-8, 2004.

36- SHAND F.L., et al.: Predictors of social anxiety in an opioid dependent sample and a control sample. Journal of anxiety disorders, 24 (1): p. 49-54, 2010.

37- CONWAY K.P., et al.: Lifetime comorbidity of DSM-IV mood and anxiety disorders and specific drug use disorders: Results from the National Epidemiologic Survey on Alcohol and Related Conditions. Journal of Clinical Psychiatry, 67 (2): p. 247-57, 2006.

38- CONWAY K.P., et al.: Association of lifetime mental disorders and subsequent alcohol and illicit drug use: Results from the National Comorbidity Survey-Adolescent Supplement. Journal of the American Academy of Child \& Adolescent Psychiatry, 55 (4): p. 280-8, 2016.

39- SAREEN J., et al.: Illicit drug use and anxiety disorders: Findings from two community surveys. Psychiatry research, 142 (1): p. 11-7, 2006.

40- CANTON J., K.M. SCOTT, and P. GLUE: Optimal treatment of social phobia: Systematic review and metaanalysis. Neuropsychiatric Disease and Treatment, 8: p. 203, 2012.

41- WITTCHEN H.U. and L. FEHM: Epidemiology and natural course of social fears and social phobia. Acta Psychiatrica Scandinavica, 108: p. 4-18, 2003.

42- FRANKEN I.H. and V.M. HENDRIKS: Screening and diagnosis of anxiety and mood disorders in substance abuse patients. The American Journal on Addictions, 10 (1): p. 30-9, 2001.

43- BECKER W.C., D.A. FIELLIN, and R.A. DESAI: Nonmedical use, abuse and dependence on sedatives and tranquilizers among US adults: psychiatric and sociodemographic correlates. Drug and alcohol dependence, 90 (2): p. $280-7,2007$. 


\section{الرهاب الإجتماعى بين مستخدمى الترا مادول والآفيونيات}

يعتبر إدمان المواد المخدرة مثكلة صحية عالمية حيث آنه يرتبط بالعديد من الإعاقات منها إعقات مهنية وعائلية ومالية ونفسية. وبسبب

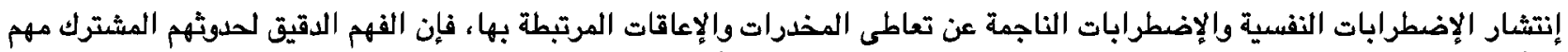

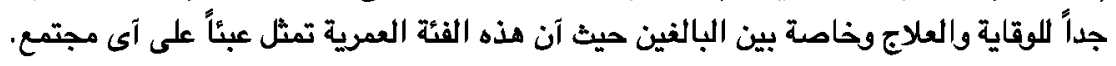

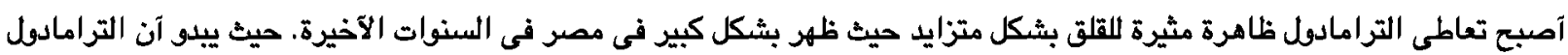

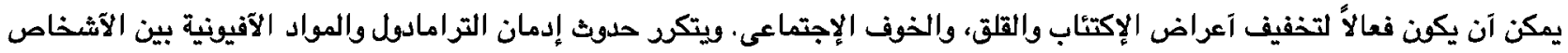

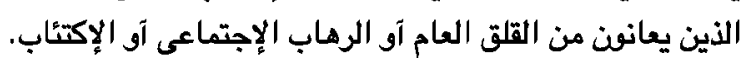

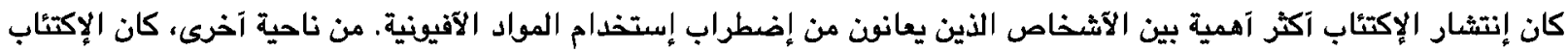

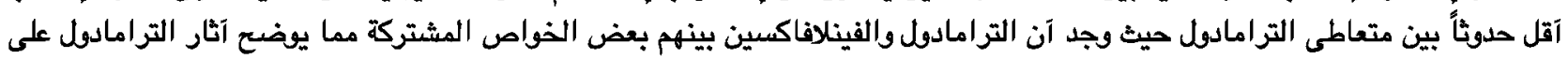

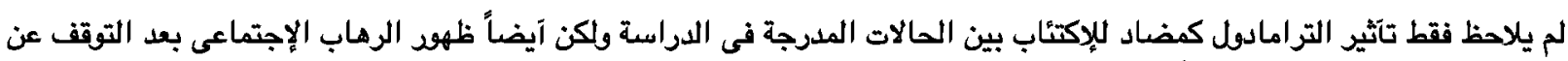

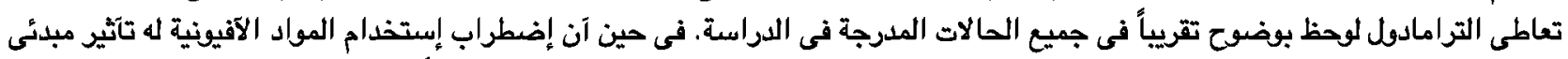
كمضاد للإكتئاب، إلا آن إستخدام المواد الآفيونية لفترات طويلة يؤدى إلى إكتئاب كبير ينخفض فين تكريجياً بعد الإنسحاب.

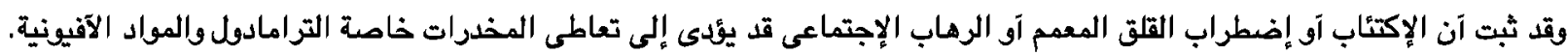

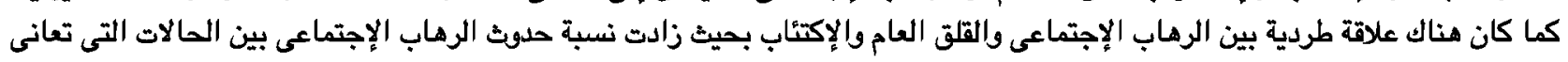
من إكتئاب آو قلق عام.

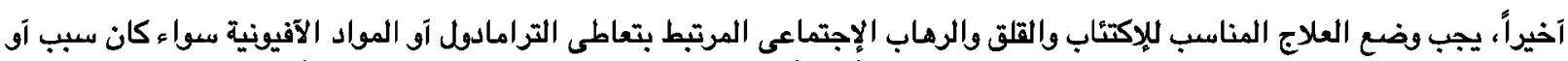

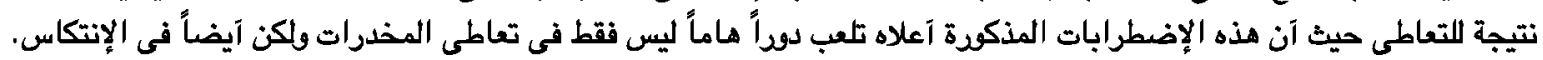

